\title{
Application of silver nanoparticles for the spectrophotometric determination of three benzimidazole anthelmintic drugs in their pharmaceutical preparations
}

\author{
Sayed M. Derayea ${ }^{1}$, Hassan Refat H. Ali ${ }^{2}$, Ahmed A. Hamad ${ }^{2 *}$, Ramadan Ali ${ }^{2}$ \\ ${ }^{1}$ Analytical Chemistry Department, Faculty of Pharmacy, Minia University, Egypt. \\ ${ }^{2}$ Department of Pharmaceutical Analytical Chemistry, Faculty of Pharmacy, Al-Azhar University, Assiut branch, Assiut 71524, Egypt.
}

\section{ARTICLE INFO \\ Article history: \\ Received on: 31/10/2016 \\ Accepted on: 26/11/2016 \\ Available online: 27/02/2017}

Key words:

Benzimidazoles; Citrate-

capped Silver nanoparticles;

Surface plasmon resonance ;

UV-visible

Spectrophotometry;

Pharmaceutical analysis.

\begin{abstract}
This article describes the application of silver nanoparticles (AgNPs) as a colorimetric probe for the simple and selective determination of three anthelmintic benzimidazole drugs namely; albendazole, flubendazole and mebendazole. The method was based on the AgNPs aggregation induced by their interaction with the cited drugs. This interaction produced a color change from yellow to blue and accompanied by the appearance of a new surface plasmon resonance peak of AgNPs measured in the range of $615-630 \mathrm{~nm}$. The linear concentration ranges of the method were 2.0-9.0, 2.0-10 and 2.2-15 $\mu \mathrm{g} \mathrm{mL}^{-1}\left(\mathrm{r}^{2}=0.9939,0.9950\right.$ and 0.9938$)$ for the studied drugs respectively. The validation of the analytical performance of the method was carefully investigated, and the results were satisfactory. This method was applied successfully to determine the three benzimidazoles in their pharmaceutical samples (tablets and suspensions) with high accuracy and precision. The suggested procedure is characterized by its simplicity since it does not involve solvent extraction or any critical reaction conditions.
\end{abstract}

\section{INTRODUCTION}

Albendazole, mebendazole and flubendazole (Fig. 1) are anthelmintic drugs belonging to benzimidazole family which are widely used in mammal with low toxicity and high effectively against a wide range of helminth species including pin worm, common hookworm, round worm, and whipworm (Köhler 2001). Benzimidazoles specifically bind to tubulin, the microtubule subunit protein, which results in disruption of the microtubule structure and function and in interference with the microtubule-mediated transport of secretory vesicles in absorptive tissues of helminthes (Köhler and Bachmann, 1981; Lacey, 1988; Jasmer et al., 2000).

\footnotetext{
* Corresponding Author Ahmed A Hamad, Department of Pharmaceutical Analytical Chemistry, Faculty of Pharmacy, Al-Azhar University, Assiut branch, Assiut 71524, Egypt. E-mail: ahmedabdulhafezhamad @ yahoo.com
}

Many analytical methods were reported for the analysis of the cited benzimidazole anthilmentics in pharmaceutical and biological samples. The techniques have included titrimetry (Mohammed et al., 1986; Basavaiah and Prameela 2003; Basavaiah and Prameela 2003; Basavaiah and Nagegowda 2004; Basavaiah et al., 2004; Basavaiah and Prameela 2004; Basavaiah et al., 2006; Basavaiah et al., 2006), spectrophotometry (Kar 1985; Sastry et al., 1997; Basavaiah and Prameela 2003; Basavaiah and Prameela 2003; Basavaiah and Nagegowda 2004; Basavaiah et al. 2004; Basavaiah and Prameela 2004; Basavaiah et al. 2006; Basavaiah et al. 2006; Kamel et al., 2008; Basavaiah et al., 2009; Tella et al., 2010; Refat et al., 2011; Swamy and Basavaiah 2014), spectrofluorimetry (Baeyens et al., 1985; Küçükkolbaşı et al., 2008; Zhao et al., 2008; Attia et al., 2016), liquid chromatography (Nakos et al., 1994; Fletouris et al., 1997; Balizs 1999; Garcia et al., 1999; Gomes and Nagaraju 2001; Kitzman et al., 2002; Danaher et al., 2007; Varghese et al., 2011) and voltammetry (de Oliveira and Stradiotto 2001). 


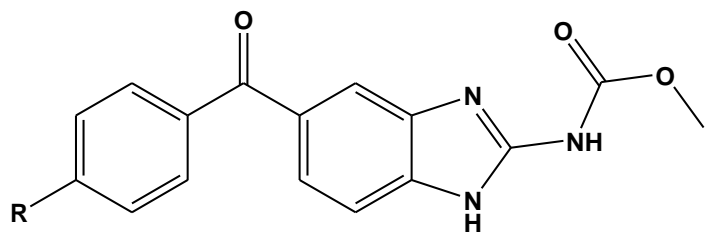

Mebendazole $(\mathbf{R}=\mathbf{H})$

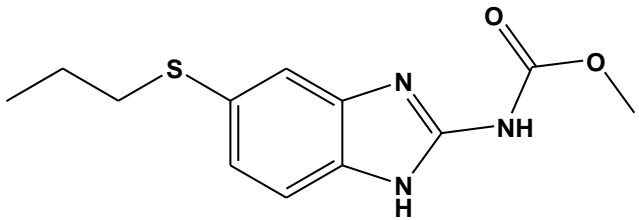

Albendazole

Flubendazole $(\mathbf{R}=\mathbf{F})$

Fig 1: Chemical structures of the investigated Benzimidazoles.

Most of the reported spectrophotometric method (Basavaiah and Prameela, 2003; Basavaiah and Prameela, 2003; Basavaiah and Nagegowda, 2004; Basavaiah et al. 2004; Basavaiah and Prameela, 2004; Basavaiah et al. 2006; Basavaiah et al. 2006; Basavaiah et al. 2009) were based on indirect determinations of the cited drugs through their oxidation and subsequent determination of the residual oxidant spectrophotometrically by reaction with another chromogenic reagent. Consequently these methods were time consuming, tedious and involved multi reagents and multi steps reactions. Although the considerable sensitivity of the spectrophotometric methods based on ion-pair complex formation (Sastry et al. 1997; Kamel et al. 2008; Swamy and Basavaiah 2014); they still suffer from the tedious procedure, time-consuming extraction step, and the use hazardous organic solvents. Those reported methods based on CT formation reaction (Sastry et al. 1997; Küçükkolbaşı et al. 2008; Refat et al. 2011) were less sensitive and consume large volumes of organic solvents.

Recently several nanometals have been synthesized and utilized for the colorimetric determination of different analytes (Ling et al., 2008; Gao et al., 2014; Patel et al., 2015). Silver nanoparticles (AgNPs) is one of the nanometals which gained much interest in chemical analysis due to its high extinction coefficient and cost effectiveness of the analysis. AgNPs have a characteristic surface plasmon resonance (SPR) peak appears at $390 \mathrm{~nm}$ which could be shifted to higher wavelength upon the interaction with the analyte accompanied by a change in the color of the colloidal solution. The reaction between nano-particles and analyte is generally based on electrostatic interactions (Ling et al. 2008; Gao et al. 2014), which causes the interparticle distance to decrease, leading to particle aggregation. The aim of the present work is to utilize citrate-capped Ag NPs as colorimetric probe for development of a simple, sensitive, efficient, and economical spectrophotometric method for the determination of three benzimidazole anthilmentics (albendazole, flubendazole and mebendazole) in bulk and pharmaceutical preparations.

\section{EXPERIMENTAL}

\section{Chemicals and materials.}

All chemicals were of analytical grade and used without further purification. Silver nitrate, sodium borohydride, sodium citrate dihydrate were purchased from Sigma-Aldrich. Albendazole powder was kindly supplied by the Egyptian International Pharmaceutical Industries Company (EIPICO, Cairo, Egypt). Flubendazole powder was kindly supplied by Unipharm (Cairo, Egypt). Mebendazole powder was obtained from The Arab Drug Company for pharmaceutical and chemical industries

Toerell \& Stenhagen (Pesez and Bartos 1974) buffer solution was prepared by mixing the aqueous solutions of; phosphoric acid $(3.5 \mathrm{~mL} / 100 \mathrm{~mL}$, El-Nasr chemical company, Cairo, Egypt), citric acid $(7 \mathrm{~g} / 100 \mathrm{~mL}$, United company for Chemical and Medical Preparations, Cairo, Egypt) and sodium hydroxide (4 g /100 mL, Isochem specifications, Cairo, Egypt). The volume was completed to $1000 \mathrm{~mL}$ with distilled water to give buffer stock solution. An appropriate volume from the stock solution was adjusted to the required $\mathrm{pH}$ with $0.1 \mathrm{M}$ hydrochloric acid (36\%, Lab-Chem fine chemicals and reagents, Cairo, Egypt).

\section{Pharmaceutical formulations}

All pharmaceutical preparations were purchased from the local market. Alzental tablet (Egyptian International Pharmaceutical Industries Company, EIPICO, Cairo, Egypt) labeled to contain $200 \mathrm{mg}$ of albendazole per tablet. Fluvermal tablet (produced by Minapharm under license of Janssen Pharmaceutica Belgium) labeled to contain $100 \mathrm{mg}$ of flubendazole per tablet. Antiver tablet (Alexandria Co. for Pharmaceuticals \& Chemical Industries, Alexandria, Egypt) labeled to contain $100 \mathrm{mg}$ of mebendazole per tablet. Alzental, Fluvermal and Antiver suspensions were labeled to contain $20 \mathrm{mg}$ per $\mathrm{mL}$ of albendazole, flubendazole and mebendazole, respectively.

\section{Instrumentation.}

Shimadzu UV-1601PC UV-Visible was used for measuring the UV-visible spectra. The Scanning spectrophotometer detector was silicon photodiode. The $\mathrm{pH}$ was measured using pH-meter, model AD11P (Adwa, Romania).

\section{Preparation of standard solution.}

An accurately weighted amount $(10 \mathrm{mg})$ of the studied drug was dissolved in $100 \mathrm{ml}$ methanol to give the stock standard solution of the drug. The stock solution was diluted with distilled 
water to obtain working standard solutions having the required drug concentrations $\left(1.0-15.0 \mu \mathrm{g} \mathrm{ml}^{-1}\right)$.

\section{Preparation of Silver Nanoparticles}

Citrate-capped Ag NPs were prepared according to the previously reported procedure (Guo et al., 2008). Silver nitrate was reduced by sodium borohydride in the presence of sodium citrate as a stabilizer. In brief, $10 \mathrm{~mL}$ of $1 \mathrm{mM}$ of silver nitrate solution was added drop wise to $30 \mathrm{~mL}$ of a freshly prepared aqueous solution of $2 \mathrm{mM}$ sodium borohydride with vigorous stirring. After $10 \mathrm{~min}, 3 \mathrm{~mL}$ of sodium citrate solution $(1 \% \mathrm{w} / \mathrm{w})$ was added to stabilize the formed yellow AgNPs. The colloidal solution was then stirred for $20 \mathrm{~min}$ and stored at $4{ }^{\circ} \mathrm{C}$ for 2 days before use.

\section{General analytical procedure:}

An appropriate volume of the working drug solution which gave a final concentration of $2-15 \mu \mathrm{g} \mathrm{mL}^{-1}$ of the studied drugs was transferred to $10 \mathrm{~mL}$ calibrated volumetric flask. A volume of $2 \mathrm{ml}$ of $0.1 \mathrm{mM}$ AgNPs solution and $1 \mathrm{ml}$ of Toerell \& Stenhagen buffer solution ( $\mathrm{pH} 8$ for albendazole and mebendazole and $\mathrm{pH} 7$ for flubendazole) were added. The solution was mixed thoroughly and allowed to stand for $10 \mathrm{~min}$. The absorbance of mixture was measured at the specified wavelength. Blank experiment was carried out in the same time following the previously mentioned procedure omitting the drug solution.

\section{Preparation of pharmaceutical samples for analysis}

\section{Tablets and suspension}

Ten tablets of the commercially available in the local market were accurately weighed and pulverized into fine powder. An accurately weighed amount of the powdered tablets (or aliquot of the suspension) equivalent to $10 \mathrm{mg}$ the drug was transferred into a $100 \mathrm{ml}$ volumetric flask and $50 \mathrm{ml}$ of methanol was added. The mixture was shacked well and sonicated for $20-30 \mathrm{~min}$. The solution was then completed to the mark with the same solvent and filtered off. Further dilutions of the filtrate were made to obtain sample solutions in the required final concentrations $(3,5$ and $7 \mu \mathrm{g}$ $\mathrm{mL}^{-1}$ ). Finally the general analytical procedure was followed mentioned above.

\section{RESULTS AND DISCUSSION}

Sliver nanoparticles are colloidal solutions of yellow color with SPR absorption at $390 \mathrm{~nm}$. Addition of citrate ions stabilize the AgNPs as the ionized polar citrate carboxyl groups on the surface of the citrate-capped AgNPs rendered the particles negatively charged, and hence dispersed from each other by the electrostatic repulsion. It was reported that positively charged molecules can effectively trigger citrate capped nanoparticles to aggregate (Ling et al. 2008; Gao et al. 2014). A positively charged compound can act as a 'molecular bridge' which initiates negatively charged nanoparticles causing them to aggregate through electrostatic attraction. It is well known that the position of the SPR band of AgNPs is much affected by the distance between the particles (Evanoff and Chumanov 2004; Kumbhar et al., 2005). Reduction of the distance between the particles during the aggregation of AgNPs shifted the SPR band to higher wavelength. Although the molecule of the studied drug contains exocyclic amino group and nitrogen hybrid rings, it could not associate with the AgNPs surface by the ligand exchange with citrate ions, due to steric hindrance. However, if the $\mathrm{pH}$ of the solution was adjusted so that makes drug molecules positively charged, then they can neutralize the electrical repulsion of silver nanoparticles (Ling et al. 2008; Gao et al. 2014),

It was observed that the addition of the studied drugs changed the color of the AgNPs solution to blue and shifted the SPR band to $615-630 \mathrm{~nm}$, depending on the structure of investigated drugs. The dramatic changes of the absorption spectra and solution color of citrate-capped Ag NPs on exposure to three benzimidazole drugs confirmed that the aggregation mechanism of AgNPs was caused by electrostatic interaction between negatively charged citrate stabilized particle surfaces and the positive charges of benzimidazole molecules.

The aggregation-based changes in the absorption band and color change of the AgNPs solution represent the basis of the proposed spectrophotometric method and the optical detection of the cited drugs.

\section{Optimization of Reaction Conditions}

AgNPs have their unique SPR band, which strongly depends on their size, shape, interparticle distance and the surrounding medium. In order to enhance the detection sensitivity of this colorimetric probe, factors facilitating the SPR change caused by the investigated drugs were critically studied and optimized.

\section{Effect of $p H$}

The adjustment of the $\mathrm{pH}$ of media is of a great importance as it is not only promote the electrical charge of analyte molecules, but also affect the stability of the nano-particles (Patel et al. 2015). Previous study indicated that the agglomeration of metallic NPs surfaces could occur at $\mathrm{pH}$ below 4 without addition of analytes due to the neutralization of NPs surface charges resulting in their aggregation and the changes in their SPR band (Basu et al., 2007). Solutions having different $\mathrm{pH}$ values $(4-10)$ were prepared and investigated to select the best $\mathrm{pH}$ for effective colorimetric sensing of benzimidazole drugs with citratecapped Ag NPs. (Fig. 2). It was found that the highest absorbance values were obtained in the $\mathrm{pH}$ range of $7-9$ for albendazole and mebendazole while in the case of flubendazole the $\mathrm{pH}$ range was 6 - 8. Higher or lower $\mathrm{pH}$ resulted in decreasing the absorbance. Therefore $\mathrm{pH}$ values of 8 for albendazole and mebendazole, and $\mathrm{pH} 7$ for flubendazole, were selected as the optimum $\mathrm{pH}$ through the current work. The optimum $\mathrm{pH}$ for flubendazole was lower than that for both albendazole and mebendazole, may be due to the lower pka value for flubendazole $(\mathrm{pka}=7.08)$ compared to albendazole $(\mathrm{pka}=9.51)$ and mebendazole $(\mathrm{pka}=8.44)$. 


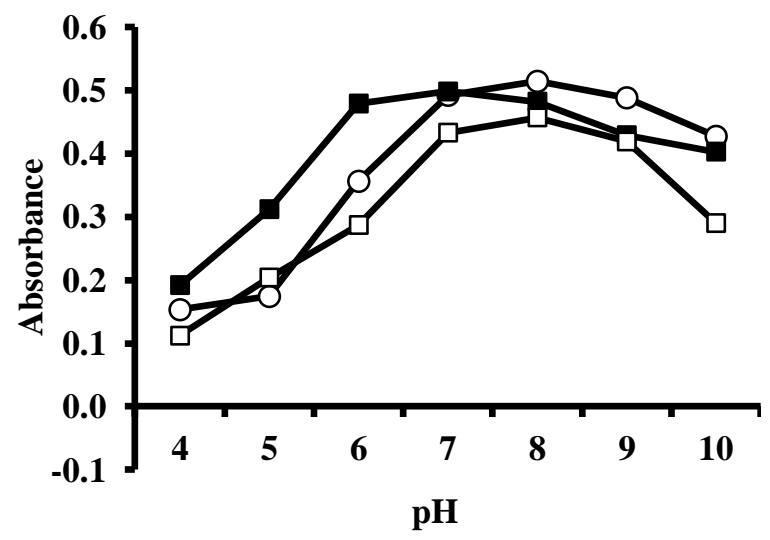

Fig 2: Effects of $\mathrm{pH}(4-10)$ of the Toerell \& Stenhagen buffer solution on the SPR absorbance of the reaction products between AgNPs and $7 \mu \mathrm{g} / \mathrm{ml}$ of albendazole (-०-), flubendazole (-m-) and mebendazole (-口-).

\section{Effect type and volume of the buffer}

Buffer solutions having different composition with the recommended $\mathrm{pH}$ value and their effects on the absorbance of the reaction product were evaluated. The studied buffers were phosphate, Britton-Robinson, borate, and Toerell \& Stenhagen buffers (Fig. 3). Toerell \& Stenhagen buffer gave the best results and it was chosen for subsequent study.

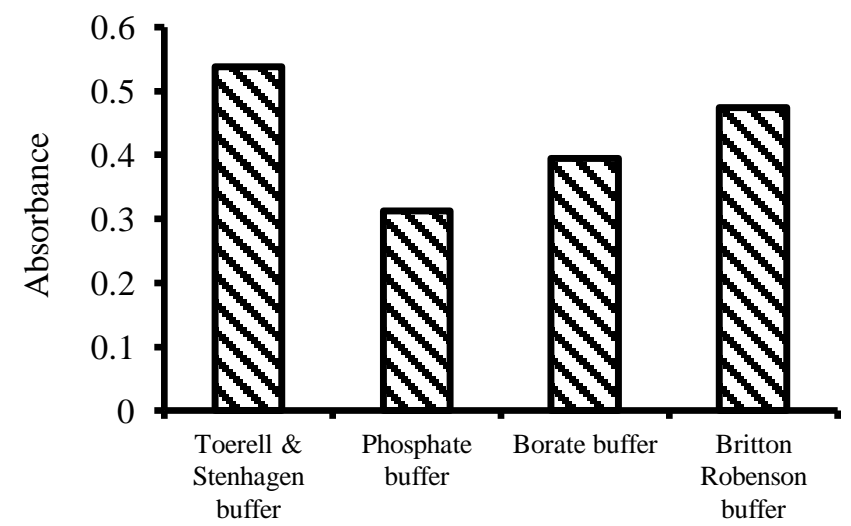

Fig 3: The influence of the buffer types ( $\mathrm{pH} 8$ ) on the SPR absorbance of the reaction product between AgNPs and albendazole $(7 \mathrm{ug} / \mathrm{ml})$.

It was observed that increasing the volume $(0.2-2.2 \mathrm{~mL})$ of Toerell \& Stenhagen buffer produced a gradual increase in the absorbance up to $0.8 \mathrm{ml}$ and remained unchanged till $1.2 \mathrm{ml}$. Further increase in the volume of the buffer slightly reduced the absorbance of the reaction product. As a result, $1.0 \mathrm{~mL}$ of the buffer was selected for the recommended general analytical procedure.

\section{Effect of AgNPs concentration}

The general analytical procedure was carried out using different concentrations of AgNPs solutions. By using a range of volumes $(0.2-2.8 \mathrm{ml})$ of $0.1 \mathrm{mM}$ AgNPs solutions, it was found that the absorbance was gradually increased by increasing the volume of the reagent. Maximum values were obtained The results indicated that $2.0 \mathrm{~mL}$ AgNPs $\left(1.0 \times 10^{-4} \mathrm{M}\right)$ solution was sufficient and satisfactory determination results of studied drugs by AgNPs detection system.

\section{Effect of reaction time and temperature}

The progress of the reaction between the studied drugs and AgNPs was monitored at different time intervals by measuring the absorbance at the specified wavelength $(615-630)$. The reaction was rapid and completed within $8 \mathrm{~min}$ as the absorbance reached its maximum value. The obtained absorbance remained constant upon standing for $30 \mathrm{~min}$. As a result all the absorbance measurements were carried out at $10 \mathrm{~min}$ after the mixing reagents.

A significant reduction in the absorbance was observed when the reaction was performed at elevated temperature (higher than $35^{\circ} \mathrm{C}$ ). The suitable temperature was $25-35^{\circ} \mathrm{C}$, so the reaction was carried out at room temperature.

\section{Method Validation}

The developed procedure was fully validated according to International Conference on Harmonisation guidelines (Branch 2005) in respect to linearity, range, accuracy, precision.

\section{Linearity and range}

A series of the standard drug solutions were analyzed using the general analytical procedure. Calibration curves were constructed by plotting absorbance against the corresponding concentration. The obtained linear concentration ranges were 2.0 9.0, 2.0-10 and 2.2-15 $\mathrm{\mu g} \mathrm{ml}^{-1}$ with correlation coefficients of $0.9939,0.9950$ and 0.9938 for albendazole, flubendazole and mebendazole respectively. Other statistical parameters were calculated and summarized in Table 1.

Table 1: Analytical parameters for determination of the investigated drugs by the proposed method.

\begin{tabular}{|c|c|c|c|}
\hline Parameters & Albendazole & Flubendazole & Mebendazole \\
\hline Linear range & $2.0-9.0$ & $2.0-10.0$ & $2.2-15$ \\
\hline Slope \pm SD & $0.0344 \pm 0.0011$ & $0.0551 \pm 0.0016$ & $0.0610 \pm 0.0020$ \\
\hline Intercept $\pm \mathrm{SD}$ & $0.0360 \pm 0.0066$ & $0.0894 \pm 0.0109$ & $-0.0006 \pm 0.0136$ \\
\hline Correlation coefficient $r^{2}$ & 0.9939 & 0.9950 & 0.9938 \\
\hline Determination coefficient, $r$ & 0.9969 & 0.9975 & 0.9969 \\
\hline Limit of detection, LOD & 0.63 & 0.66 & 0.74 \\
\hline Limit of quantitation LOQ & 1.91 & 1.99 & 2.23 \\
\hline
\end{tabular}

* the concentration is in $\mu \mathrm{g} / \mathrm{ml}$. 
Table 2: Intra- and inter-day analysis for the evaluation of the accuracy and precision using the proposed method.

\begin{tabular}{cccc}
\hline Conc. level & \multicolumn{1}{c}{ \% Recovery ${ }^{\mathbf{a}} \pm$ SD } & Flubendazole \\
\hline $\boldsymbol{\mu} \mathbf{~ m l}^{\mathbf{1}}$ & Albendazole & Mebendazole & $100.23 \pm 0.70$ \\
3 & $100.22 \pm 1.26$ & Intra-day assay & $100.28 \pm 1.31$ \\
5 & $100.31 \pm 1.10$ & $99.37 \pm 1.39$ & $99.97 \pm 1.07$ \\
7 & $99.97 \pm 1.09$ & $100.87 \pm 1.53$ & $100.83 \pm 1.00$ \\
\hline Mean & $\mathbf{1 0 0 . 1 7 \pm 0 . 1 8}$ & $\mathbf{1 0 0 . 3 5 6} \pm \mathbf{0 . 8 5}$ & \\
\hline 3 & $99.78 \pm 1.47$ & Inter-day assay & $101.36 \pm 1.35$ \\
5 & $100.07 \pm 0.49$ & $98.15 \pm 1.61$ & $99.96 \pm 0.79$ \\
7 & $99.91 \pm 1.07$ & $100.22 \pm 0.67$ & $100.57 \pm 1.41$ \\
\hline Mean & $\mathbf{9 9 . 9 2} \pm \mathbf{0 . 1 5}$ & $100.74 \pm 0.85$ & $\mathbf{1 0 0 . 1 6} \pm \mathbf{0 . 1 7}$ \\
\hline
\end{tabular}

${ }^{a}$ the value is the average of three determinations.

Table 3: Analysis of the studied benzimidazole in their pharmaceutical formulations using the proposed and reported methods.

\begin{tabular}{|c|c|c|c|c|}
\hline \multirow[t]{2}{*}{ Dosage forms } & \multicolumn{2}{|c|}{$\%$ Recovery $^{\mathrm{b}} \pm$ SD } & \multirow[t]{2}{*}{ F-value ${ }^{c}$} & \multirow[t]{2}{*}{ t-test } \\
\hline & Proposed method & Reported method & & \\
\hline Alzental $200 \mathrm{mg}$ tablet & $101.07 \pm 1.06$ & $100.01 \pm 1.39$ & 1.72 & 1.14 \\
\hline Alzental suspension ${ }^{a}$ & $100.22 \pm 0.88$ & $99.60 \pm 1.15$ & 1.71 & 0.80 \\
\hline Fluvermal $100 \mathrm{mg}$ tablet & $100.06 \pm 1.41$ & $98.99 \pm 1.04$ & 1.84 & 1.23 \\
\hline Fluvermal suspension $^{a}$ & $100.37 \pm 0.83$ & $100.52 \pm 1.8$ & 4.70 & 0.14 \\
\hline Antiver $100 \mathrm{mg}$ Tablet & $100.02 \pm 1.09$ & $100.63 \pm 1.59$ & 2.13 & 0.59 \\
\hline Antiver suspension ${ }^{\mathrm{a}}$ & $99.85 \pm 1.39$ & $99.50 \pm 1.72$ & 1.53 & 0.30 \\
\hline
\end{tabular}

${ }^{\text {a }}$ the concentration of suspension is $20 \mathrm{mg} / \mathrm{mL}$.

${ }^{\mathrm{b}}$ the value is the mean of five and three replicate measurement for the proposed and reported methods, respectively.

${ }^{\mathbf{c}}$ The tabulated values of $\mathrm{t}$ - and F-test at $95 \%$ confidence limit are 1.943 and 6.95. respectivelv

\section{Accuracy and precision}

In order to determine the accuracy and precision at the intra- and inter-day levels, the standard drugs solutions at three different concentrations within the working range were prepared and analyzed by the proposed method in three replicates. The analysis was carried out within the same day in case of intra-day analysis or on three consecutive days for inter-day analysis (Table 2). The closeness of the percentage recoveries to $100 \%$ indicated the satisfactory accuracy of the proposed method. The calculated relative standard deviations did not exceeded $2 \%$ in both intra- and inter-day analysis indicated the excellent precision of the proposed procedure at both level of repeatability and intermediate precision

\section{Selectivity and effect of Interferences}

The effect of commonly utilized excipients in drug formulation was studied. The specificity of the method was conducted to prove that the drug is free from interference of commonly used tablet excipients. The investigated benzimidazole drugs were studied in the presence of various excipients e.g. lactoseas glucose, fructose, lactose, maltose, sucrose, and magnesium stearate which were prepared in the proportion corresponding to those which are used in the final dosage form (20 $\mu \mathrm{g} \mathrm{ml}^{-1}$ ) and analyzed with the proposed method. It was found that there was no significant interferences effect by the studied excipients on the results of the method.

\section{Application to pharmaceutical dosage forms}

The proposed method was applied to the determination of the investigated benzimidazolea in dosage forms (tablet and suspension). The results obtained were statistically compared with those of the reported methods for albendazole (Tella et al. 2010) flubendazole (Baeyens et al. 1985) and mebendazole (Baeyens $e t$ $a l$. 1985) by applying the Student's $t$-test for accuracy and $F$-test for precision.

The calculated $t$ and $F$-values at 95\% confidence level, and results in Table 3 showed that there is no difference between the calculated and theoretical values of both $t-$ and F-values indicating good levels of accuracy and precision of the proposed method, respectively. The sensitivity, simplicity and minimal volume of samples make the method suitable for routine analysis of the studied drugs in quality control laboratories.

\section{CONCLUSION}

This article demonstrated the use of silver nanoparticles as chromogenic agent for the determination of three anthelmintic drugs. The reagent involved in the proposed method was inexpensive, readily available, and fairly stable in aqueous solution compared to many reagents used in other methods. The developed procedures did not include any critical reaction conditions such as rigid $\mathrm{pH}$ control, tedious or time-consuming extraction or heating steps.

Moreover, the proposed analytical methodology is considered a green procedure which could be applied for monitoring and optical detection of investigated benzimidazole drugs in pure and pharmaceutical dosage forms. Hence, the methods can be used in routine analysis of these drugs in quality control laboratories 
Financial support and sponsorship: Nil.

Conflict of Interests: There are no conflicts of interest.

\section{REFERENCES}

Attia KA, Mohamed AA, Emara MS. Application of quinonebased fluorophore for spectrofluorimetric determination of albendazole in pure form and pharmaceutical formulation. Analytical Methods, 2016.

Baeyens W, Fattah FA, De Moerloose P. Fluorimetric analysis of mebendazole and flubendazole with hydrogen peroxide. Journal of Pharmaceutical And Biomedical Analysis, 1985; 3:397-404.

Balizs G. Determination of benzimidazole residues using liquid chromatography and tandem mass spectrometry. Journal of Chromatography B: Biomedical Sciences and Applications, 1999; 727:167-177.

Basavaiah K, Nagegowda P. Three new methods for the assay of albendazole using $\mathrm{N}$-chlorosuccinimide. Journal of Scientific and Industrial Research, 2004; 63:835-841.

Basavaiah K, Nagegowda P, Ramakrishna V. Titrimetric and spectrophotometric methods for the assay of albendazole in non-aqueous medium. Proceedings of the National Academy of Sciences, India, Section A: Physical Sciences, 2004; 74:271-283.

Basavaiah K, Prameela H. Two simple methods for the estimation of albendazole and its dosage forms using chloramine-T. Il Farmaco, 2003; 58:527-534.

Basavaiah K, Prameela H. Titrimetric and spectrophotometric determination of albendazole with bromate and methyl orange. Oxidation Communications, 2004; 27:177-185.

Basavaiah K, Prameela HC. Use of an oxidation reaction for the quantitative determination of albendazole with chloramine- $T$ and acid dyes. Analytical sciences, 2003; 19:779-784.

Basavaiah K, Ramakrishna V, Somashekar B. Assay of albendazole using N-bromosuccinimide. The Indian Pharmacist, 2006; 5.

Basavaiah K, Ramakrishna V, Somashekar B, Anil Kumar U. Sensitive titrimetric and spectrophotometric methods for the assay of albendazole in pharmaceuticals using sodium periodate. Analytical Chemistry: An Indian Journal, 2006; 2:159-166.

Basavaiah K, Tharpa K, Prasad NR, Hiriyanna S, Vinay K. Simple, sensitive and rapid spectrophotometric determination of albendazole based on redox and complex formation using $\mathrm{N}$ bromosuccinimide. Proceedings of the Indian National Science AcademyPart A: Physical Sciences, 2009; 75:1.

Basu S, Ghosh SK, Kundu S, Panigrahi S, Praharaj S, Pande S, Jana S, Pal T. Biomolecule induced nanoparticle aggregation: effect of particle size on interparticle coupling. Journal of colloid and interface science, 2007; 313:724-734.

Branch SK. Guidelines from the international conference on harmonisation (ICH). Journal of pharmaceutical and biomedical analysis, 2005; 38:798-805

Danaher M, De Ruyck H, Crooks SR, Dowling G, O'Keeffe M. Review of methodology for the determination of benzimidazole residues in biological matrices. Journal of Chromatography B, 2007; 845:1-37.

de Oliveira MF, Stradiotto NR. Voltammetric assay of albendazole in pharmaceutical dosage forms. Analytical letters, 2001; 34:377-387.

Evanoff DD, Chumanov G. Size-controlled synthesis of nanoparticles. 2. Measurement of extinction, scattering, and absorption cross sections. The Journal of Physical Chemistry B, 2004; 108:1395713962.

Fletouris D, Botsoglou N, Psomas I, Mantis A. Determination of the marker residue of albendazole in milk using ion-pair liquid chromatography and fluorescence detection. Analytica chimica acta, 1997; 345:111-119.

Gao M, Lin R, Li L, Jiang L, Ye B, He H, Qiu L. Label-free silver nanoparticles for the naked eye detection of entecavir. Spectrochimica Acta Part A: Molecular and Biomolecular Spectroscopy, 2014; 126:178-183.
Garcia JJ, Bolás-Fernández F, Torrado JJ. Quantitative determination of albendazole and its main metabolites in plasma. Journal of Chromatography B: Biomedical Sciences and Applications, 1999; 723:265-271.

Gomes AR, Nagaraju V. High-performance liquid chromatographic separation and determination of the process related impurities of mebendazole, fenbendazole and albendazole in bulk drugs. Journal of pharmaceutical and biomedical analysis, 2001; 26:919 927.

Guo J-Z, Cui H, Zhou W, Wang W. Ag nanoparticle-catalyzed chemiluminescent reaction between luminol and hydrogen peroxide. Journal of Photochemistry and Photobiology A: Chemistry, 2008; 193:8996.

Jasmer DP, Yao C, Rehman A, Johnson S. Multiple lethal effects induced by a benzimidazole anthelmintic in the anterior intestine of the nematode Haemonchus contortus. Molecular and biochemical parasitology, 2000; 105:81-90.

Kamel MS, Barsoum B, Sayed R. Spectrophotometric microdetermination of anthelmintic drug in pure form and pharmaceutical formulation by ion-pair complexation. Journal of Applied Sciences Research, 2008; 4:1242-1248.

Kar A. Spectrophotometric determination of mebendazole in pure and dosage forms by complexation with potassium bismuth (III) iodide. Analyst, 1985; 110:1031-1033.

Kitzman D, Cheng K-J, Fleckenstein L. HPLC assay for albendazole and metabolites in human plasma for clinical pharmacokinetic studies. Journal of pharmaceutical and biomedical analysis, 2002; 30:801813.

Köhler P. The biochemical basis of anthelmintic action and resistance. International journal for parasitology, 2001; 31:336-345.

Köhler P, Bachmann R. Intestinal tubulin as possible target for the chemotherapeutic action of mebendazole in parasitic nematodes. Molecular and biochemical parasitology, 1981; 4:325-336.

Küçükkolbaşı S, Gündüz B, Kılı̨̧ E. Development of a spectrofluorimetric method for determination of albendazole in tablets. Analytical Letters, 2008; 41:104-118.

Kumbhar AS, Kinnan MK, Chumanov G. Multipole plasmon resonances of submicron silver particles. Journal of the American Chemical Society, 2005; 127:12444-12445.

Lacey E. The role of the cytoskeletal protein, tubulin, in the mode of action and mechanism of drug resistance to benzimidazoles. International journal for parasitology, 1988; 18:885-936.

Ling J, Sang Y, Huang CZ. Visual colorimetric detection of berberine hydrochloride with silver nanoparticles. Journal of pharmaceutical and biomedical analysis, 2008; 47:860-864.

Mohammed F, Sidhom M, Hussein H. Titrimetric and spectrophotometric determination of mebendazole and flubendazole using N-bromosuccinimide. Bull. Pharm. Sci. Assiut University, 1986; 9:92-104.

Nakos DS, Botsoglou NA, Psomas IE. Ion-pair isolation and liquid chromatographic determination of albendazole, oxfendazole, oxibendazole, and thiabendazole residues in milk. Journal of Liquid Chromatography \& Related Technologies, 1994; 17:4145-4155.

Patel GM, Rohit JV, Singhal RK, Kailasa SK. Recognition of carbendazim fungicide in environmental samples by using 4 aminobenzenethiol functionalized silver nanoparticles as a colorimetric sensor. Sensors and Actuators B: Chemical, 2015; 206:684-691.

Pesez M, Bartos J. Colorimetric and fluorimetrlc analysis of organic compounds. Analysis of Organic Compounds and Drugs, Dekker, 1974.

Refat MS, Mohamed GG, Fathi A. Spectrophotometric Determination of Albendazole Drug in Tablets: Spectroscopic Characterization of the Charge - transfer Solid Complexes. Chinese Journal of Chemistry, 2011; 29:324-332.

Sastry C, Sarma Varahabhatia A, Prasad U, Lakshmi C. A note on the estimation of some benzimidazole anthelmintics in pharmaceutical preparations by ion-pair extraction method. Indian drugs, 1997; 34:102104.

Swamy N, Basavaiah K. Simple and rapid spectrophotometric assay of albendazole in pharmaceuticals using iodine and picric acid as CT 
complexing agents. Brazilian Journal of Pharmaceutical Sciences, 2014; 50:839-850.

Tella AC, Olabemiwo OM, Salawu MO, Obiyenwa GK. Developing a Spectrophotometric method for the estimation of Albendazole in solid and suspension forms. International Journal of Physical Sciences, 2010; 5:379-382.

Varghese S, Vasanthi P, Ravi T. Simultaneous densitometric determination of ivermectin and albendazole by high-performance thinlayer chromatography. JPC-Journal of Planar Chromatography-Modern TLC, 2011; 24:344-347.

Zhao GY, Wu H, Dong SL, Du LM. Study on the inclusion interaction of methylated- $\beta$-cyclodextrins with albendazole by spectrofluorimetry and its application. Chinese Chemical Letters, 2008; 19:951-954.

\section{How to cite this article:}

Derayea SM, Ali HRH, Hamad AA, Ali R. Application of silver nanoparticles for the spectrophotometric determination of three benzimidazole anthelmintic drugs in their pharmaceutical preparations. J App Pharm Sci, 2017; 7 (02): 076-082. 